\title{
Perspective of Immunopathogenesis and Immunotherapies for Kawasaki Disease
}

\author{
Lung Chang ${ }^{1,2,3,4+}$, Horng-Woei Yang ${ }^{3 \dagger}$, Tang-Yu Lin ${ }^{5}$ and Kuender D. Yang ${ }^{1,3,4,5,6,7 *}$ \\ ${ }^{1}$ Department of Pediatrics, MacKay Memorial Hospital, Taipei, Taiwan, ${ }^{2}$ Division of Infectious Disease, MacKay Children's \\ Hospital, Taipei, Taiwan, ${ }^{3}$ Department of Medical Research, MacKay Memorial Hospital, New Taipei City, Taiwan, \\ ${ }^{4}$ Department of Medicine, Mackay Medical College, New Taipei City, Taiwan, ${ }^{5}$ Division of Allergy-Immunology-Rheumatology, \\ MacKay Children's Hospital, Taipei, Taiwan, ${ }^{6}$ Department of Microbiology \& Immunology, National Defense Medical Center, \\ Taipei, Taiwan, ${ }^{7}$ Institute of Clinical Medicine, National Yang Ming Chiao Tung University, Taipei, Taiwan
}

Kawasaki Disease (KD) is an acute inflammatory illness that mostly occurs in children below 5 years of age, with intractable fever, mucocutaneous lesions, lymphadenopathy, and lesions of the coronary artery (CAL). KD is sharing clinical symptoms with systemic inflammatory syndrome in children (MIS-C) which is related to COVID-19. Certain genes are identified to be associated with $\mathrm{KD}$, but the findings usually differ between countries and races. Human Leukocyte Antigen (HLA) allele types and toll-like receptor (TLR) expression are also correlated to KD. The acute hyperinflammation in KD is mediated by an imbalance between augmented $\mathrm{T}$ helper 17 (Th17)/Th1 responses with high levels of interleukin (IL)-6, IL-10, IL-17A, IFN- $\gamma$, and IP-10, in contrast to reduced Th2/Treg responses with lower IL-4, IL-5, FoxP3, and TGF- $\beta$ expression. KD has varying phenotypic variations regarding age, gender, intravenous immunoglobulin (IVIG) resistance, macrophage activation and shock syndrome. The signs of macrophage activation syndrome (MAS) can be interpreted as hyperferritinemia and thrombocytopenia contradictory to thrombocytosis in typical KD; the signs of KD with shock syndrome (KDSS) can be interpreted as overproduction of nitric oxide (NO) and coagulopathy. For over five decades, IVIG and aspirin are the standard treatment for KD. However, some KD patients are refractory to IVIG required additional medications against inflammation. Further studies are proposed to delineate the immunopathogenesis of IVIG-resistance and KDSS, to identify high risk patients with genetic susceptibility, and to develop an ideal treatment regimen, such as by providing idiotypic immunoglobulins to curb cytokine storms, NO overproduction, and the epigenetic induction of Treg function.

Keywords: coronary artery aneurysm, coronavirus disease 2019, immunotherapy, intravenous immunoglobulin resistance, Kawasaki disease, Kawasaki disease shock syndrome, multisystem inflammatory syndrome in children, Th17/Treg imbalance

\section{INFECTION VERSUS AUTOIMMUNITY IN KAWASAKI DISEASE}

Kawasaki Disease (KD), previously known as mucocutaneous lymph node syndrome was first reported by Tamisaku Kawasaki in 1974 (1). KD is a systemic inflammatory disease complicated with medium-sized vasculitis that is found mostly in children younger than 5 years of age, with at least four out of the five clinical features: pleomorphic skin rashes, bilateral non-purulent 
conjunctivitis, changes in oral mucosal: dry fissured and erythema of lips, and strawberry tongue, changes in the appearance of peripheral extremities: indurative angioedema of the hands and feet, followed by skin desquamation, and cervical lymphadenopathy (at least $1.5 \mathrm{~cm}$ in diameter) (1-3). Pathogens such as $S$. aureus, streptococci, coronavirus, enterovirus, EpsteinBarr (EB) or rhinovirus virus had been suspected to be associated with KD (4-8). In East Asia, Bacillus CalmetteGuérin (BCG) vaccination is a standard procedure into infants. There, about $40 \%$ of the KD patients develop a reactive skin erythema and scaling at the site where BCG was inoculated. This suggests that the reaction at the BCG inoculation site is related to a cross-reaction of BCG antigen or a bystander of the hyperinflammatory reaction of KD (9). Asymptomatic infection may lead to KD in children with an underlying genetic predisposition (10). However, no invariable single pathogen readout in the sera from patients of KD has been observed (11). Although siblings of KD patients have a six to 10 times higher risk developing $\mathrm{KD}$ than those without a family history, there is no evidence of a contagious transmission of $\mathrm{KD}$ in day care centers or among hospitalized patients $(12,13)$. It is debatable whether $\mathrm{KD}$ is a post-infectious hyperinflammation reaction, an autoinflammatory syndrome or an autoimmune disorder (1416). Inflammation-inducing substances may play an important role in $\mathrm{KD}$, such as those originating from pathogens, pathogenassociated molecular patterns (PAMPs), toxins (superantigens), and antigens from injured or infected-host cells which behaved as damage-associated molecular patterns (DAMPs) that are causing the hyperinflammatory response of KD (17).

In 2005, a novel human coronavirus named human coronavirus New Haven $(\mathrm{HCoVNH})$ is reported to be linked to a cluster of $\mathrm{KD}$ in $\mathrm{New}$ Haven, by evidence of positive RT-PCR detection of $8 / 11$ vs. $1 / 22$ in a case-control study (7). This correlation between $\mathrm{KD}$ and $\mathrm{HCoVNH}$ is not observed in Taiwan. Viral RNA of HCoVNH or HCoV-NL63 in nasopharyngeal secretions is not detected among 53 consecutive KD subjects (8). Recently, during the pandemic of coronavirus disease 2019 (COVID-19), more than 1,000 cases of KD-like multisystem inflammatory syndrome in children (MIS-C) have been reported (18). MIS-C shares similar symptoms with KD, such as fever, skin rash, conjunctivitis, mucous membrane involvement. Some MIS-C patients even meet the full diagnostic criteria for KD (19). Over $80 \%$ of the patients are positive in serological test for anti-severe acute respiratory syndrome coronavirus 2 (SARS-CoV-2) spike protein antibodies, but $<30 \%$ of them had detectable viral RNA in upper respiratory tract $(18,20-24)$. The immunologic markers of KD and MIS-C are also overlapping, as such inflammatory cytokines of interleukin (IL)-1, IL-6, IL-8, and IL-17 are usually elevated. The fact that MIS-C occurs after SARS-CoV-2 infection presenting a KD-like disorder suggests that both $\mathrm{KD}$ and MIS-C have similar pathogenesis of autoimmune etiology induced by certain viral infection (25). Therefore, the algorithm for diagnosis and treatment of typical and atypical (incomplete) KD in children has been adopted for the early recognition and management of the MIS-C, such as treatment with IVIG and corticosteroids (26). Interestingly, the MIS-C cases are mostly reported from
Italy, France, UK, and USA but not found in Asia, where the incidence of KD is 10 times higher than that in Western countries $(24,27)$. It is worth to mention previous reports of increasing $\mathrm{KD}$ incidences after hepatitis $\mathrm{B}$ and influenza vaccinations (28-30). There is also evidence of autoimmune disease flared up after SARS-CoV-2 vaccination recently (31). Now the COVID-19 vaccines have been widely applied to young adults and old adults but not young children. It deserves our concern whether COVID-19 mass vaccination in children might increase the MIS-C. It is reasonable to concern that the incidence of MIS-C might increase after the extensive vaccination against SARS-CoV-2, in which the cross-reactivity of $\mathrm{T}$ lymphocytes and vaccine antigen in the presence of adjuvants might raise the risk of autoimmune vasculitis (32). These observations suggest that children in Western countries are more susceptible to coronavirus-related $\mathrm{KD}$-like vasculitis, which apparently has a different etiology from the KD vasculitis in the Asian population.

\section{IMMUNOPATHOGENESIS OF KAWASAKI DISEASE}

Various infectious disease cause mucocutaneous rashes in combination with neutrophilia and elevated C-reactive protein (CRP). However, KD is not contagious, the vasculitis is regarded as the result of hyperinflammatory reactions which are attributed to immune responses $(14,16)$. Patients with $\mathrm{KD}$ are presenting with an increased $\mathrm{T}$ helper cell 17 (Th17) count, diminished regulatory $\mathrm{T}$ cell (Treg) reaction, and a higher neutrophil vs. lymphocyte $(\mathrm{N} / \mathrm{L})$ ratio in the KD cases of IVIG resistance and coronary complications. This implied an imbalance between pro-inflammatory and immunoregulatory responses $(33,34)$.

We first demonstrated that in children with $\mathrm{KD}$, the immune activation marker CD40L is highly expressed on $\mathrm{T}$ cells and platelets, and that the overexpression of inducible nitric oxide synthase (iNOS) is associated with elevated nitric oxide (NO) levels in blood samples of KD patients before IVIG therapy $(35,36)$. These findings indicate that the intensity of innate and adaptive immune reactions is reversed after IVIG therapy. $\mathrm{T}$ cell polarization is skewed toward the Th2 pathway as a response to IVIG therapy, a high eosinophil count and elevated IL-5 levels are favorable markers for the success of an IVIG treatment, in contrast, lower initial eosinophil counts, IL-4, and IL-5 cytokine levels are related to a refractory response of IVIG $(37,38)$. KD patients have prominent Th17 immune responses and diminished Treg pathway transcription factor, FoxP3 expression while compared to a febrile control group without KD (39).

The susceptibility to KD is also related to an alteration of the Treg response in respect to polymorphisms of the transforming growth factor (TGF)- $\beta$ signaling pathway genes TGF- $\beta 2$ and SMAD3, which downregulate the Treg immune response (39, 40). Moreover, some KD patients are presenting with a phagocyte activation syndrome due to the overproduction of interferon (IFN)- $\gamma$, and its downstream mediators of interferoninduced protein (IP)-10 and tumor necrosis factor (TNF)- $\alpha$ 
TABLE 1 | Different phenotypes and characters of Kawasaki disease.

\begin{tabular}{|c|c|c|c|}
\hline \multirow[t]{2}{*}{ Phenotypes } & \multicolumn{2}{|c|}{ Kawasaki disease (KD) } & \multirow[t]{2}{*}{ KD shock syndrome (KDSS) } \\
\hline & Typical KD & Atypical KD & \\
\hline Criteria & $\geqq 4 / 5$ & $<4 / 5$ & $\geqq 4 / 5+$ shock \\
\hline Myocarditis & $5 \%$ & $20 \%$ & $20 \%$ \\
\hline Age (year) (avg) & $0.5-5.0(2.0)$ & Frequent $<0.5$ or $>5$ & $2-12(3.5)$ \\
\hline Platelets (1,000/ul) & $>350$ & $>450$ & High or low \\
\hline WBC $\left(/ \mathrm{mm}^{3}\right)$ & $>10,000$ & $>15,000$ & Variable \\
\hline Pyuria & Some & Frequent & Frequent \\
\hline CRP (mg/dl) & $3-15$ & $>3$ & $>10$ \\
\hline Procalcitonin (ng/ml) & $>0.5$ & Variable & $>1.0$ \\
\hline Ferritin (ng/ml) & $100-200$ & $100-200$ & $>500$ \\
\hline Coagulopathy & No & Some & Often \\
\hline D-dimer (ng/ml) & $<1,000$ & $<1,000$ & $>1,000$ \\
\hline Cytokines & IL-6, IL-10, IP-10 & IL-6 & IL-6, INF- $\gamma$, IL-10 \\
\hline IVIG Resistance (\%) & 15 & >15 (delayed Rx) & 40 \\
\hline Fatality (\%) & 0.1 & Unknown & 2 \\
\hline
\end{tabular}

WBC, white blood cell; CRP, C-reaction protein; IL, interleukin; INF, interferon; IP, interferon- $\gamma$ induced protein; IVIG, intravenous immunoglobulin.

(41). In addition to early neutrophilia, KD patients are usually suffering from thrombocytosis in later stages of the disease (42). Taken together, these studies indicate that the kinetic immune responses in $\mathrm{KD}$ consists of an early augmentation of the innate immunity, follow by an imbalance between Th17/Th1 and Th2Treg responses of the adaptive immunity. This assumption is consistent with observations made in autopsies, showing early necrotizing vasculitis with innate phagocyte activation is followed by the remodeling of coronary thrombosis with lymphocyte infiltration and the formation of aneurysms in the adaptive immunity phase $(43,44)$. These findings also suggested that a comprehensive immunotherapy may be required to modify the immunopathogenesis of $\mathrm{KD}$, depending on the progression of the disease.

\section{IMMUNOGENETICS AND CLINICAL PHENOTYPES OF KAWASAKI DISEASE}

KD can be categorized into different phenotypes according to clinical presentations and the severity of the disease (Table 1). Typical KD presents as a systemic vasculitis with fever of more than 5 days and meets the aforementioned clinical features. Patients with the typical KD criteria but fever $<5$ days may be diagnosed with KD if coronary aneurysm, dilatation and/or lesion is found. Children with prolonged fever and suspected of having KD but not fulfilling the complete diagnostic criteria are regarded as incomplete or atypical $\mathrm{KD}$. Children with $<6$ months or more than 5 years of age tend to have atypical $\mathrm{KD}$, which usually is associated with delayed in diagnosis and treatment $(45,46)$. These atypical $\mathrm{KD}$ patients tend to have a high risk of IVIG resistance and coronary arterial abnormalities $(45,47,48)$. Adults with coronary lesions are often contemporarily or retrospectively diagnosed with atypical or incomplete $\mathrm{KD}(49,50)$.
A severe form of $\mathrm{KD}$ complication with life-threatening myocardial dysfunction and hypotension is known as KD shock syndrome (KDSS). According to a population-based study in Taiwan, KDSS patients are older and higher risk of coronary artery complications (51). As shown in Table 1, levels of CRP and procalcitonin are elevated in the KDSS group. Ferritin $(>500-1,000 \mathrm{ng} / \mathrm{ml})$ and D-dimer $(>1,000-$ $4,000 \mathrm{ng} / \mathrm{ml}$ ) are also significantly higher in children with KDSS (52-54). The inflammatory mediators, phagocyte activation and coagulopathy profiles are very similar between KDSS and MIS-C (26). In general, hyperferritinemia in KDSS is thought to originate from macrophage activation syndrome (MAS), and thus is concurrent with hypertriglyceridemia, anemia, and hypercytokinemia. Moreover, the pathogenesis of the shock syndrome in $\mathrm{KD}$ may be explained by the overproduction of nitric oxide. KDSS is more frequently taking a complicated course with pulmonary symptoms, acute kidney injury (AKI), pancreatitis, hepatitis, and neurological disorders $(53,55,56)$. The systemic cytokine storms in KD and KDSS are similar, with hypercytokinemia of IL-6, IL-10, IL-17, IP-10, and monocyte chemoattractant protein (MCP)-1. However, the levels of IL-6 and IL-10 are significantly higher in $\operatorname{KDSS}(54,57)$. There is a risk of thrombosis in KDSS patients who are frequently associated with lower platelet counts, and coagulopathy $(52,58)$. As the incidence of KD and KDSS differs widely among ethnicities and countries, a contribution of environmental factors and the diverse genetic background to different clinical phenotypes of $\mathrm{KD}$ may be assumed.

\section{ETHNICAL DIFFERENCES AND GENETIC SUSCEPTIBILITY OF KAWASAKI DISEASE}

$\mathrm{KD}$ is prevalent in many East Asian countries, e.g., in Japan, China, Korea and Taiwan $(2,17,59,60)$. For children younger 
than 5 years, the highest incidence has been observed in Japan (more than 250 cases per 100,000 children). In India, the incidence is the lowest (only 4.5 per 100,000 children) $(61,62)$. Children of Japanese ethnicity have the highest incidence of KD in Hawaii, before other Asians, Chinese, and Caucasian children (61). Several genes have been linked to the susceptibility of $\mathrm{KD}$, e.g., B-lymphoid tyrosine kinase (BLK), cysteine-aspartic acid protease (CASP)3, CD40, Fc fragment of IgG receptor IIA (Fc $\gamma$ RIIA), inositol-triphosphate 3 kinase C (ITPKC), and calcium release-activated calcium channel protein (ORAI)1 (6365). Human leukocyte antigen (HLA)-BW22J2 is prevalent in the Japanese population but not in Caucasians (66). In Korean children, the frequency of HLA-DRB1* 11 is a risk factor for KD with coronary artery lesions (CAL), HLA-DRB1*09 has been shown to be protective (67). In Taiwan, the HLA-DRB1 is associated with susceptibility to $\mathrm{KD}$, and the MHC-class-Ichain-related gene A (MICA) A4 in KD is protecting children with $\mathrm{KD}$ from developing $\mathrm{CAL}$, which has been validated in a genome-wide association case-control study (GWAS) in the Taiwanese population (68-70). Since the role of HLA is to present antigenic molecules to the immune system, a specific HLA subtype activate $\mathrm{T}$ cells and induce a hyperinflammation response depending on the HLA polymorphisms among races and ethnicities (71).

In addition to HLA subtypes, we have discovered that TGF- $\beta 2$ and SMAD3 variants are associated with $\mathrm{KD}$ in the population of Taiwan (40). A dominant T allele of rs2243250 in the IL-4 gene is conferring a significant protective effect against the development of CAL $(p=0.006)$ (72).

In the ongoing COVID-19 pandemic, as an illness that manifests with $\mathrm{KD}$-like features, MIS-C is thought to be a rare complication associated with COVID-19 (18). The atypical KDlike symptoms alert physicians to recognize it early and to adopt an adequate treatment for MIS-C patients. The connection between MIS-C and COVID-19 suggests that post-infectious autoimmune vasculitis depends considerably on the individual genetic background. It is also of concern that the incidence of MIS- $C$ might increase after the extensive vaccination against SARS-CoV-2, where the cross-reactivity of $\mathrm{T}$ lymphocytes and the vaccine antigen in the presence of adjuvants might raise the risk of autoimmune vasculitis (32). The contribution of the Th17/Treg imbalance to autoimmunity is different between MIS$\mathrm{C}$ and $\mathrm{KD}$, because the Th17 mediators are elevated in both diseases but the immunosuppressive mediators stem cell factor (SCF), negative regulator of INF- $\gamma$ (TWEAK), and adenosine deaminase (ADA) in KD are lower than in MIS-C. This suggests that $\mathrm{KD}$ and MIS-C patients do require different strategies for immunotherapy (25).

\section{EPIGENETIC FACTORS IN THE IMMUNOREGULATION OF KAWASAKI DISEASE}

In addition to a genetic predisposition of Th17/Treg imbalance, the epigenetic regulation of DNA methylation on innate and adaptive immune genes is also associated with KD. Patients with DNA hypomethylation on the promoter $\mathrm{CpG}$ islands of immune activation genes have the tendency of being susceptible to KD and IVIG resistance (73-76). In the acute stage of $\mathrm{KD}$, most of the changes in $\mathrm{CpG}$ island methylation have been identified as hypomethylation (97\%) (76). These genes are associated with the mRNA expression of toll-like receptors (TLRs 1, 2, 4, 5, 8, and 9) (74). Similarly, innate immunity genes such as Fc $\gamma$ RIIA, IL-10, and S100A8 are reported being hypomethylated in KD patients (74-76). The DNA-hypomethylation is reversed after IVIG treatment, which indicates that epigenetic methylation plays an important role in the pathogenesis of $\mathrm{KD}$.

In the meantime, miRNAs have been disclosed to be an ideal biomarker of $\mathrm{KD}$, this may assist in the differentiation of $\mathrm{KD}$ from other febrile diseases, based on miRNAs expression profile at $\mathrm{C}_{\mathrm{T}}$ (miR-1246)- $\mathrm{C}_{\mathrm{T}}$ (miR-4436b-5p) and $\mathrm{C}_{\mathrm{T}}$ (miR-197-3p)- $\mathrm{C}_{\mathrm{T}}$ (miR-671-5p) (77). The changes of miRNA expression associated with Treg cells in KD patients before and after IVIG treatment have been documented $(78,79)$.

The epigenetic control of Treg cells has been demonstrated mainly via FoxP3 expression pathway (80). In addition to the individual genetic background, environmental factors are also contributing to the epigenetic profiles and functional markers of Treg subpopulations (tTreg, pTreg, and iTreg). Hence, studying Treg subsets may potentially help to predict and hints the clues of how to prevent Th17-mediated autoimmune diseases $(80,81)$. Given the fact that the immunopathogenesis of acute KD appeared to include prominent Th17 cell activation and accompanied by a lower regulatory $\mathrm{T}$ cell response which will be reversed after IVIG treatment $(39,80-82)$, we postulated that the dynamics of Treg populations, which are regulated by genetic and epigenetic modifications, may be considered to be useful biomarkers and potentially therapeutic targets of KD.

\section{EVOLVEMENT OF IMMUNOTHERAPIES FOR KAWASAKI DISEASE}

The standard treatment of $\mathrm{KD}$ in the acute febrile stage has evolved through the past 50 years, and consists either of a combination of aspirin, antibiotics, and corticosteroids, or of a combination of IVIG, aspirin, and corticosteroids (Figure 1) $(1,26,83-99)$. In the 1970's, the era before IVIG therapy, aspirin considered to be a better choice than antibiotics or corticosteroids $(1,83)$. However, neither high dose $(80-100 \mathrm{mg} / \mathrm{kg})$ nor low dose $(30-60 \mathrm{mg} / \mathrm{kg})$ of aspirin was able to reduce the prevalence of coronary artery aneurysm (CAA) formation in KD patients $(45,46)$. After introducing IVIG treatment since the late 1980 's, the recommended standard regimen is a combination of aspirin and IVIG therapy. The optimal dosage of IVIG for $\mathrm{KD}$ is a single high dose of $2 \mathrm{gm} / \mathrm{kg}$, it turned out to be more effective than protocol of $1 \mathrm{gm} / \mathrm{kg} /$ day for 2 days, or $400 \mathrm{mg} / \mathrm{kg} /$ day for 5 days $(46,84)$. Before the IVIG therapeutic regimen had been developed, the incidence of CAA was $25 \%$ and the mortality rate was $1-2 \%$ in $\mathrm{KD}$ patients $(1,2,83)$. After that, the sequelae of CAA declined to $3-4 \%$ with a mortality of $0.1 \%(46,59,60)$. 


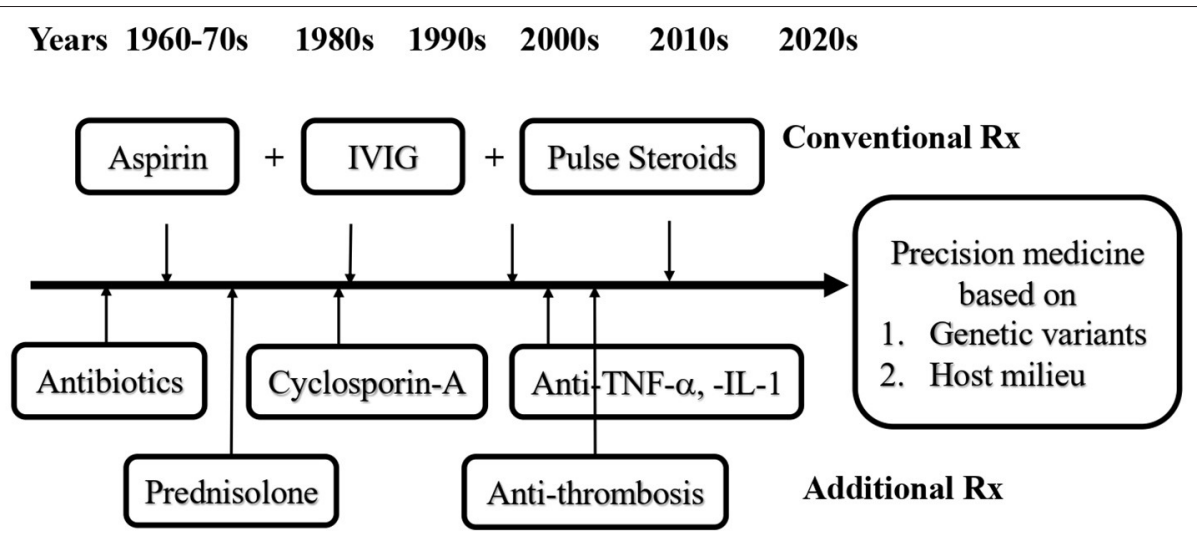

FIGURE 1 | Evolvement of immunotherapies for Kawasaki disease (KD). The conventional treatment (Rx) for KD has been evolved from antibiotics, aspirin, corticosteroids, IVIG and aspirin plus IVIG, aspirin, and/or pulsed corticosteroids through the past 50 years. In KD patients with IVIG resistance or KDSS, additional Rx for refractory KD requires cyclosporin-A, anti-cytokines, and/or anti-thrombotic treatment, depending on the complications. In the era of precision medicine, to screen and to understand the genetic variants and internal milieu of KD patients in advance may help to prevent KD in patients from IVIG resistance or KDSS.

While most of the KD patients respond well to the combination of aspirin and IVIG, still $10-20 \%$ of the patients are refractory to this therapy $(46,91,94,96)$. In these cases, the treatment with IVIG and pulsed corticosteroids has led to a better clinical outcome $(87,89)$.

Corticosteroids are commonly considered as a therapy for autoimmune disease. The use of corticosteroids in $\mathrm{KD}$ before the era of IVIG had an increased morbidity of CAA at $64.7 \%$ vs. only $20 \%$ when treated with antibiotics or $11 \%$ when treated with aspirin $(1,83)$. In a meta-analysis, the combination of IVIG with pulsed corticosteroids is found to significantly reduce the risk of CAL compared with IVIG alone (7.6 vs. $18.9 \%$; OR: 0.3 ; 95\% CI $0.20-0.46$ ) (89). In addition to pulsed corticosteroids, KD patient refractory to IVIG may benefit from therapies with cyclosporin, anti-TNF- $\alpha$, or antiIL-1 (Figure 1) (93-95, 97). This may be explained by the immunopathogenesis of KD: An augmented proinflammatory cytokine storm in the febrile stage is followed by intensified Treg cell function after IVIG treatment, due to genetic expression and epigenetic modification of immune-regulatory genes. Certain hallmark complications of KD such as KDSS, MAS, or CAA are usually associated with IVIG resistance, suggesting there might be different immunopathological mechanisms present among these patients. Thus, KD patients with underlying various immune phenotypes might require a tailored comprehensive immunotherapy to cease disease progression. Several scoring systems have been developed to predict IVIG resistant KD, e.g., the Kobayashi Score, which is useful for the prediction and prevention of CAL in the Japanese population but shows poor sensitivity and specificity in Western countries $(87,96)$.

KD patients with IVIG resistance usually present with a protracted course of fever and elevated IL- 6 cytokine levels (86). It is reasonable to apply anti-IL-6 therapy for refractory KD patients, because the serum IL-6 level is correlated with IVIG resistance (94). However, in a study of four patients with IVIG-resistant $\mathrm{KD}$ showed good response to treatment with anti-IL-6, two of them still developed CAA (95). Some studies have reported the association of high IL-6, IL-10, and TNF- $\alpha$ cytokine levels with refractory $\operatorname{KD}(46,86)$. Lower IL-5 levels and eosinophil counts are also correlated with IVIG resistance $(37,38)$. Meanwhile, the allele rs2243250T of the IL-4 gene is found to confer protection against CAL (72). KD patients with genetic diversity background may require different criteria to predict a possible resistance to IVIG and individualized anti-cytokine treatment. A detailed scoring system should include clinical symptoms and signs, the individual's immune genotype and laboratory parameters, to guide a precise anti-inflammatory therapy and improve clinical outcomes.

Patients with KDSS are usually suffering from complications of coagulopathy, embolism, and thrombosis, which require antithrombotic therapy in addition to IVIG, corticosteroids and inotropic medications $(53,54,58,98)$. The pathophysiology of the coagulopathy is based on host antigen presenting cells (APCs) carrying HLA subtype(s) which interact with PAMPs or DAMPs and induce an innate defense with defensin and type I interferons, followed by an efficient adaptive immunity of Th1 cell immunity and Th2 humoral immunity. Abnormal host-antigen interactions are leading to Th17/Th1; Th2-Treg imbalance and cytokine storm through the expression of IL6, IL-17A, and IL-10, which manifest in KDSS as systemic vasculitis, thrombosis, and shock. In the era of precision medicine, to correct the imbalance of the Th1-Th17/Th2Treg response in refractory KD or KDSS, we should not only consider genetic variants, but also HLA subtypes and the host milieu (Figure 1). Homeostasis of vitamins and microbiota may enhance the function of Tregs and suppress the response to cytokines (26, 92, 99-102). For instance, almost all KD patients $(98.7 \%)$ had significantly lowered $25(\mathrm{OH})$-vitamin D levels $(<30 \mathrm{ng} / \mathrm{mL})$ than age-matched non-KD patients $(78.6 \%, p<$ 0.0001) (92). A low level of vitamin $\mathrm{D}$ is linked with gut 
dysbiosis and inflammation in KD with vascular morbidities (99). Therefore, knowing the genetic variants and host milieu of highrisk patients might be beneficial in preventing complications of KD.

\section{PERSPECTIVE OF IMMUNOTHERAPIES FOR KD PATIENTS RESISTANT TO CONVENTIONAL TREATMENT}

Based on the understanding of the immunopathogenesis of $\mathrm{KD}$ and the resistance to IVIG, we would like to suggest a stepwise approach to IVIG-resistance and KDSS, as described in Figure 2 and below:

\section{Targeting Cytokine Storm}

Hypercytokinemia of TNF- $\alpha$ and IL- 6 is the hallmark in KD patients with IVIG resistance $(103,104)$. Thus, some studies demonstrated that anti-TNF- $\alpha$ (infliximab) or antiIL-1 (anakinra) can provide as an adjunctive therapies for IVIG resistant KD (97). The therapeutic effect of single pro-inflammatory cytokines antagonist based on monoclonal antibody may be suboptimal; a combined regimen or targeting with polyclonal antibodies will be more efficient. Although $\mathrm{KD}$ and MIS-C are sharing similar clinical presentations, the Th17 and Th1 mediators Il-6, IL-17A, TNF- $\alpha$, and IP10 are more prominently increased in $\mathrm{KD}$ than in MIS-C $(25,46,86)$. This fact advocates that targeting IL-17A and
TNF $\alpha$ should be considered in IVIG resistant KD patients. In contrast to children with MIS-C without IL-17A or TNF $\alpha$ over production, a combination of IVIG and IL-1receptor antagonist (e.g., Anakinra) might be the preferred therapeutic strategy $(25,105)$. Acute kidney injury is a serious complication in some KD patients. Particularly, those with KDSS and hypercytokinemia require plasma exchange or continuous renal replacement therapy (56). In critical conditions, extracorporeal membrane oxygenation (ECMO) is indicated for $\mathrm{KD}$ patients with life-threatening cardiac dysfunction or hemodynamic instability in KDSS refractory to IVIG, corticosteroids and inotropic agents $(106,107)$.

2. Targeting Th17/Treg Imbalance

Genetic and epigenetic alterations in the Treg pathways have been found in patients with KD. The Treg cell development and induction are largely affected by the endogenous milieu, such as vitamins and metabolites of microbiota (101, 108-112). The lower vitamin D levels have been linked to hyperinflammation in COVID-19 and thrombotic complications (111-113). Vitamin D deficiency had been also shown to be associated with IVIG resistant KD and coronary artery complications $(92,110)$. In addition to vitamin $\mathrm{D}$, gut microbiota coordinates mesenchymal stem cells (MSCs) and relieve experimental autoimmune disorders (114-117). Accumulated evidence suggests that vitamin D supplementation and exosomes derived from MSCs might be useful in treating inflammatory diseases with a cytokine storm

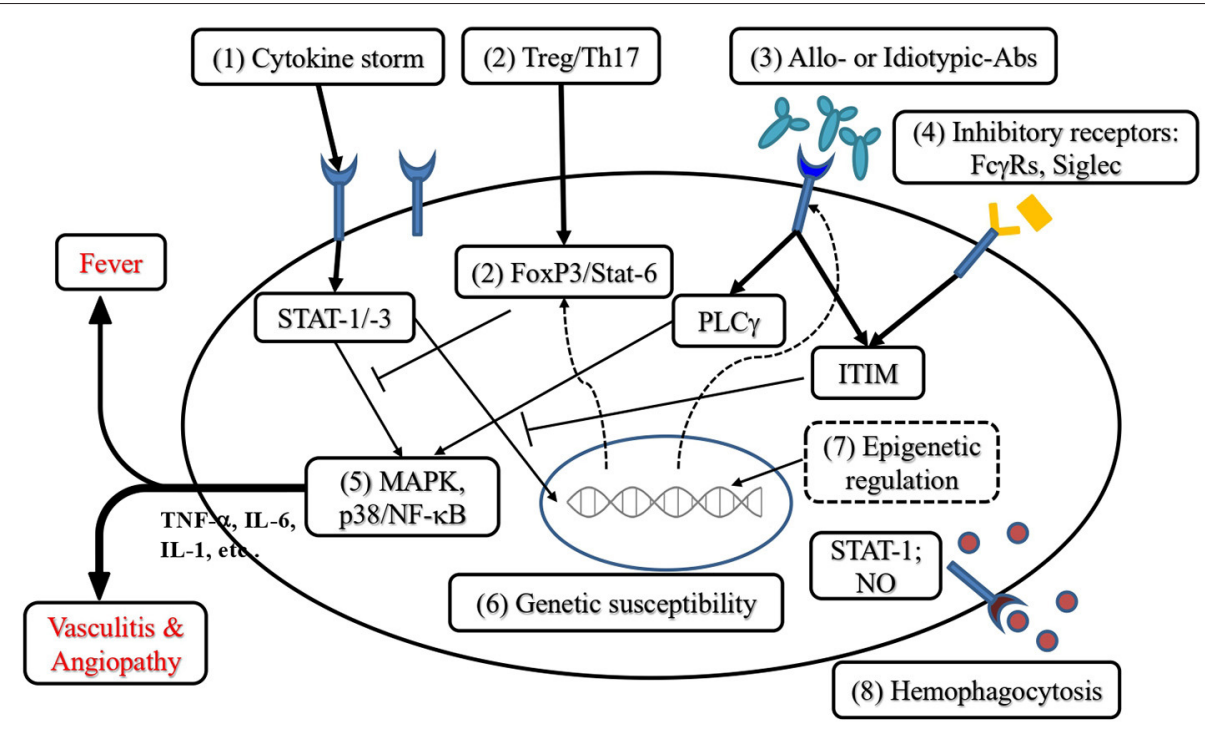

FIGURE 2 | Perspective of immunotherapies for KD refractory to conventional treatment. (1) Targeting the cytokine storm: Anti-TNF- $\alpha$ and anti-IL-1 have been used to rescue IVIG resistance. In addition, other Th17 and Th1 cytokines are also candidates for therapeutic targets. (2) Addressing the Th17/Treg imbalance can be achieved by augmentation of Th2 or Treg polarization, including the enhancement of FoxP3 expression. (3) Blockade or immunoregulation by allotypic and idiotypic IgG provides immunoregulation of KD. (4) Enhancement of immunoinhibitory receptors transduces the immunoreceptor tyrosine-based inhibitory motif (ITIM) to inhibit cytokine production. (5) Targeting the signal transduction of mitogen-activated protein kinases (MAPK) including p38 phosphorylation to suppress cytokine (TNF- $\alpha$, IL-6, IL-1, etc.) production. (6) Screening genetic variants related to KD with IVIG resistance protects KD patients from coronary complications. (7) Epigenetic regulation of Treg immune responses reverses the Th17/Treg imbalance in KD with IVIG resistance. (8) Anti-hemophagocytosis can be achieved by targeting IFN- $\gamma$ and TNF- $\alpha$ as well as the inhibition of their downstream effector STAT-1 (signal transducer and activator of transcription 1) or nitric oxide (NO) synthase activation ( $\rightarrow$ indicates activation; $\perp$ indicates inhibitory regulation; - - - > indicates epigenetic regulation). 
(114-116), which might be adopted for the treatment of KD with IVIG resistance.

3. Neutralization or Immunoregulation by Allotypic and Idiotypic IgG

Despite IVIG remains irreplaceable for its immunomodulatory activity in the treatment of $\mathrm{KD}$, a certain portion (10-20\%) of KD patients shows resistance to IVIG (118). The mechanism of IVIG immunoregulatory effect is attributed to neutralizing antibodies, anti-idiotypic antibodies, isotypic/allotypic IgG fractions, and Fc fragments which bind to inhibitory Fc receptors $(119,120)$. The Fc $\gamma$ RIIB is an inhibitory $\mathrm{Fc}$ receptor on human phagocytes and $\mathrm{B}$ cells with diverse biological functions due to polymorphic variants (121). The genetic variants or isoforms of Fc $\gamma$ RIIB can reshape autoimmune disorders, as well as $\mathrm{KD}(121,122)$. Several articles report that maternal anti-idiotypic IgG modulate immunoregulatory phenotypes of B cells and Th17 cells in utero or by adoptive cell transfer (123-125). Further efforts should focus on the roles of IVIG antibody fractions and recombinant IgG fragments for the precision treatment of KD.

4. Enhancement of Immunoinhibitory Receptors

The inhibition of the hyperinflammation could be mediated by the immunoreceptor tyrosine-based inhibition motif (ITIM) through its cytoplasmic tail (126). The ITIMcontaining receptors belong to the immunoglobulin receptor superfamily with a consensus sequence of $\mathrm{I} / \mathrm{V} / \mathrm{LxYxxL} / \mathrm{V}$ (where $\mathrm{x}$ represents any amino acid) and are docking to proteins with $\mathrm{SH} 2$ domains, among the protein-tyrosine phosphatases like Shp1 and Shp2 (127). The inhibitory Fc $\gamma$ RIIB mediates immunomodulation through an inhibitory ITIM $(121,127)$. In Caucasian KD patients, polymorphisms of Fc $\gamma$ RIIB is related to resistance against IVIG treatment (122). Studies have shown that Fc fragments play a pivotal role in the immunosuppression for autoimmune disorders $(121,122$, $128,129)$. The Fc domains of IgG isotypes are N-glycosylated at asparagine-297 and $30 \mathrm{~N}$-glycans have been identified and implicated to participate in varying effector functions of IgG (130-132). The N-glycans of the Fc domain with galactosylated glycans are associated with pro-inflammatory diseases; in contrast, the degree of sialogalactosylation on the $\mathrm{N}$-glycosylated $\mathrm{Fc}$ domains in antibody preparations are proportional to anti-inflammatory effect (132).

The CD24Fc is a fusion compound consisting of a Fc domain and a CD24 sialoglycoprotein. It shows a protective effect in an animal model of virus-mediated respiratory inflammation. A commercial version of CD24Fc has been examined in a phase three clinical trial for COVID-19 immunomodulatory treatment (133). The highly sialylated CD24 glycoprotein is able to induce immunosuppression by the ligation of a sialoglycan to sialic acid immunoglobulinlike lectin-10 (Siglec-10), and activates multiple physiological effects, such as mediating a driving force to cancer, damping excessive tissue inflammation, and inducing immune tolerance in pregnancy (134-136). A novel cell membraneinsertable lipid-modified synthetic sialoglycan has been investigated for immunomodulatory properties (137). It inhibits in vitro overactivation of neutrophils by extracellular neutropil traps (NETosis), in which the biological mechanism is mediated by ITIM-associated SHP-1. In short, these glycanbased immunomodulators may be applied in the future to treat KD patient refractory with IVIG resistance.

5. Targeting Signal Transduction

Phosphoproteomics have shown that the overactivation of mitogen-activated kinase (MAPK) signaling cascades are involved in the pathogenesis of $\operatorname{KD}(25,138)$. In addition, autoantibodies to MAPK and members of the casein kinase family (CSNK1A1, CSNK2A1, CSNK1E1) are also found in children with KD-like MIS-C (25). A synthetic lipid-modified sialoglycopeptide which inserts into cell membranes and mediates a cis-binding to Siglec-9 to inhibit MAPK activation, it has the potential for therapeutic suppression of autoimmune inflammation (139). Taken together, the specific targeting of the MAPK and CSNK pathways by protein kinase inhibitors, such as the modified sialoglycan that binds to Siglec-9, may be the key to anti-inflammatory treatment for the IVIG refractory KD.

6. Screening Genetic Variants and HLA Subtypes

Polymorphisms of immune-related genes including HLA subtypes are critical to the etiology and severity of $\mathrm{KD}(40,65-$ 72). In Korea and Taiwan, the HLA-DRB1 is significantly associated with susceptibility of $\operatorname{KD}(67,69)$, and we found that (MICA) A4 is a protective locus to protect KD patients from CAL (68). Recently, HLA-A02, B35, and C04 have been indicated to interact with superantigen-like motif of SARS-CoV-2 spike glycoprotein in MIS-C patients (140). In addition, genetic polymorphisms of the Treg pathway genes are associated with the susceptibility to $\mathrm{KD}(40)$. The gene expression of TLR1, 2, 4, 5, 8, and 9 are also involved in the pathogenesis of $\mathrm{KD}(74)$. To combine all the potential susceptible genes, we may be able to establish a specific genetic screening platform for the prediction of $\mathrm{KD}$. This may help identify patients with a high risk of developing KD and offer early intervention and prevention of the disease.

7. Epigenetic Regulation of Treg Immune Responses

Epigenetic modulations of DNA methylation and miRNA expression have been implicated in the pathogenesis of $\mathrm{KD}$ (73-77). Given the fact that $\mathrm{T}$ cell regulatory functions are affected by the epigenetic modulation of FoxP3, strategies for providing homeostasis of Treg immune responses might be applied to correct the Th17/Treg imbalance in complicated KD patients $(78-81,114-117)$.

8. Inactivate Hemophagocytic Reactions

Some patients with KDSS or MIS-C have evidence of MAS, in which laboratory studies revealed anemia, hyperferritinemia and hypertriglyceridemia. Macrophage activation is a result of the overexpression of Th1 mediators, such as IFN- $\gamma$ and TNF- $\alpha$, followed by the activation of Stat-1 and nuclear factor (NF)- $\mathrm{B}$. This pathophysiological response will lead to coagulopathy, hemophagocytosis and vasculitis $(14,16,20,21,141,142)$. The autoimmune-induced MAS is also occurring in patients with rheumatic diseases, including juvenile idiopathic arthritis, systemic lupus erythematosus and in patients with $\mathrm{KD}(41,141,143,144)$. 
In this situation, a combination of IVIG with pulsed corticosteroids or administration of cyclosporin-A, anti-IL-1, and/or anti-TNF- $\alpha$ might be indicated (41, 97, 143-145).

In summary, autoimmune vasculitis in $\mathrm{KD}$ and KDSS is mediated by a hyperinflammation response due to Th17/Treg imbalance, presumably associated with genetic variants of HLA, Fc $\gamma$ RIIA, and/or epigenetic dysregulation. In the cases of IVIG resistant KD and KDSS, there are different phenotypes, susceptibility and immunopathogenesis, which in turn could be utilized for early prediction, prevention, and precision treatment. Regarding standard immunotherapies for $\mathrm{KD}$, a consensus has been reached toward a combination of IVIG and aspirin with an additional pulse therapy of corticosteroids in high-risk patients. In refractory $\mathrm{KD}$, individualized treatments such as anti-cytokine therapy or epigenetic induction should be considered to correct the Th17/Treg imbalance and cytokine storm hyperinflammation.

\section{REFERENCES}

1. Kawasaki T, Kosaki F, Okawa S, Shigematsu I, Yanagawa H. A new infantile acute febrile mucocutaneous lymph node syndrome (MLNS) prevailing in Japan. Pediatrics. (1974) 54:271-6.

2. Wang CL, Wu YT, Liu CA, Kuo HC, Yang KD. Kawasaki disease: infection, immunity and genetics. Pediatr Infect Dis J. (2005) 24:9981004. doi: 10.1097/01.inf.0000183786.70519.fa

3. Lin MT, Wu MH. The global epidemiology of Kawasaki disease: review and future perspectives. Glob Cardiol Sci Pract. (2017) 2017:e201720. doi: 10.21542/gcsp.2017.20

4. Reller M, DeCristofaro J, Schwartz DC. Coronary aneurysms in a patient with atypical Kawasaki syndrome and a streptococcal infection. Pediatr Cardiol. (1984) 5:205-7. doi: 10.1007/BF02427046

5. Kikuta H, Taguchi Y, Tomizawa K, Kojima K, Kawamura N, Ishizaka A, et al. Epstein-Barr virus genome-positive T lymphocytes in a boy with chronic active EBV infection associated with Kawasaki-like disease. Nature. (1988) 333:455-7. doi: 10.1038/333455a0

6. Marchette NJ, Melish ME, Hicks R, Kihara S, Sam E, Ching D. Epstein-Barr virus and other herpesvirus infections in Kawasaki syndrome. J Infect Dis. (1990) 161:680-4. doi: 10.1093/infdis/161.4.680

7. Esper F, Shapiro ED, Weibel C, Ferguson D, Landry ML, Kahn JS. Association between a novel human coronavirus and Kawasaki disease. I Infect Dis. (2005) 191:499-502. doi: 10.1086/428291

8. Chang LY, Lu CY, Shao PL, Lee PI, Lin MT, Fan TY, et al. Viral infections associated with Kawasaki disease. J Formos Med Assoc. (2014) 113:14854. doi: 10.1016/j.jfma.2013.12.008

9. Yamazaki-Nakashimada MA, Unzueta A, Berenise GamezGonzalez L, Gonzalez-Saldana N, Sorensen RU. BCG: a vaccine with multiple faces. Hum Vaccin Immunother. (2020) 16:1841-50. doi: 10.1080/21645515.2019.1706930

10. Rowley AH. Is Kawasaki disease an infectious disorder? Int J Rheum Dis. (2018) 21:20-5. doi: 10.1111/1756-185X.13213

11. Torii Y, Horiba K, Hayano S, Kato T, Suzuki T, Kawada JI, et al. Comprehensive pathogen detection in sera of Kawasaki disease patients by high-throughput sequencing: a retrospective exploratory study. BMC Pediatr. (2020) 20:482. doi: 10.1186/s12887-020-02380-7

12. Dajani AS, Taubert KA, Gerber MA, Shulman ST, Ferrieri P, Freed M, et al. Diagnosis and therapy of Kawasaki disease in children. Circulation. (1993) 87:1776-80. doi: 10.1161/01.CIR.87.5.1776

13. Burns JC, Newburger JW. Genetics insights into the pathogenesis of Kawasaki disease. Circ Cardiovasc Genet. (2012) 5:2778. doi: 10.1161/CIRCGENETICS.112.963710

\section{AUTHOR CONTRIBUTIONS}

LC summarized the KD studies in Mackay Children Hospital for drafting the manuscript. H-WY drafted and revised the manuscript. T-YL collected the references and discussed the scheme for the writing of the manuscript. KY designed the article's outline and organized the information for the review, which has been approved by all authors before submission. All authors contributed to the article and approved the submitted version.

\section{FUNDING}

This study received funding from the following grant: MOST 110-2314-B-195-011 (to LC and H-WY), and MOST 110-2314B-195 -012 -MY3 (to KY), from the Ministry of Science and Technology of Taiwan.

14. Marrani E, Burns JC, Cimaz R. How should we classify Kawasaki disease? Front Immunol. (2018) 9:2974. doi: 10.3389/fimmu.2018.02974

15. Rhim JW, Kang HM, Han JW, Lee KY. A presumed etiology of Kawasaki disease based on epidemiological comparison with infectious or immunemediated diseases. Front Pediatr. (2019) 7:202. doi: 10.3389/fped.2019.0 0202

16. Sakurai Y. Autoimmune aspects of Kawasaki disease. J Investig Allergol Clin Immunol. (2019) 29:251-61. doi: 10.18176/jiaci. 0300

17. Lee KY. Pneumonia, acute respiratory distress syndrome, and early immune-modulator therapy. Int J Mol Sci. (2017) 18:20388. doi: 10.3390/ijms18020388

18. Levin M. Childhood multisystem inflammatory syndrome a new challenge in the pandemic. $N$ Engl J Med. (2020) 383:393-5. doi: 10.1056/NEJMe2023158

19. Loke YH, Berul CI, Harahsheh AS. Multisystem inflammatory syndrome in children: is there a linkage to Kawasaki disease? Trends Cardiovasc Med. (2020) 30:389-96. doi: 10.1016/j.tcm.2020.07.004

20. Riphagen S, Gomez X, Gonzalez-Martinez C, Wilkinson N, Theocharis P. Hyperinflammatory shock in children during COVID-19 pandemic. Lancet. (2020) 395:1607-8. doi: 10.1016/S0140-6736(20)31094-1

21. Verdoni L, Mazza A, Gervasoni A, Martelli L, Ruggeri M, Ciuffreda M, et al. An outbreak of severe Kawasaki-like disease at the Italian epicentre of the SARS-CoV-2 epidemic: an observational cohort study. Lancet. (2020) 395:1771-8. doi: 10.1016/S0140-6736(20)31103-X

22. Cheung EW, Zachariah P, Gorelik M, Boneparth A, Kernie SG, Orange JS, et al. Multisystem inflammatory syndrome related to COVID-19 in previously healthy children and adolescents in New York City. J Am Med Assoc. (2020) 324:294-6. doi: 10.1001/jama.2020.10374

23. Pouletty M, Borocco C, Ouldali N, Caseris M, Basmaci R, Lachaume $\mathrm{N}$, et al. Paediatric multisystem inflammatory syndrome temporally associated with SARS-CoV-2 mimicking Kawasaki disease (Kawa-COVID-19): a multicentre cohort. Ann Rheum Dis. (2020) 79:999-1006. doi: 10.1136/annrheumdis-2020-217960

24. Feldstein LR, Rose EB, Horwitz SM, Collins JP, Newhams MM, Son MBF, et al. Multisystem inflammatory syndrome in US children and adolescents. $N$ Engl J Med. (2020) 383:334-46. doi: 10.1056/NEJMoa2021680

25. Consiglio CR, Cotugno N, Sardh F, Pou C, Amodio D, Rodriguez L, et al. The immunology of multisystem inflammatory syndrome in children with COVID-19. Cell. (2020) 183:968-81e7. doi: 10.1016/j.cell.2020.09.016

26. Chen MR, Kuo HC, Lee YJ, Chi H, Li SC, Lee HC, et al. Phenotype, susceptibility, autoimmunity, and immunotherapy between Kawasaki disease and coronavirus disease-19 associated 
multisystem inflammatory syndrome in children. Front Immunol. (2021) 12:632890. doi: 10.3389/fimmu.2021.632890

27. Kaushik A, Gupta S, Sood M, Sharma S, Verma S. A systematic review of multisystem inflammatory syndrome in children associated with SARS-CoV-2 infection. Pediatr Infect Dis J. (2020) 39:e3406. doi: 10.1097/INF.0000000000002888

28. Miron D, Fink D, Hashkes PJ. Kawasaki disease in an infant following immunisation with hepatitis B vaccine. Clin Rheumatol. (2003) 22:4613. doi: $10.1007 / \mathrm{s} 10067-003-0785-3$

29. Jeong SW, Kim DH, Han MY, Cha SH, Yoon KL. An infant presenting with Kawasaki disease following immunization for influenza: A case report. Biomed Rep. (2018) 8:301-3. doi: 10.3892/br.2018.1043

30. Chang A, Islam S. Kawasaki disease and vasculitis associated with immunization. Pediatr Int. (2018) 60:613-7. doi: 10.1111/ped.13590

31. Vera-Lastra O, Ordinola Navarro A, Cruz Domiguez MP, Medina G, Sanchez Valadez TI, Jara LJ. Two cases of graves' disease following SARS-CoV-2 vaccination: an autoimmune/inflammatory syndrome induced by adjuvants. Thyroid. (2021). doi: 10.1089/thy.2021.0142

32. Blumenthal JA, Burns JP. Complexities of the COVID-19 vaccine and multisystem inflammatory syndrome in children. Pediatr Investig. (2020) 4:299-300. doi: 10.1002/ped4.12232

33. Jia S, Li C, Wang G, Yang J, Zu Y. The T helper type 17/regulatory T cell imbalance in patients with acute Kawasaki disease. Clin Exp Immunol. (2010) 162:131-7. doi: 10.1111/j.1365-2249.2010.04236.x

34. Cho HJ, Bak SY, Kim SY, Yoo R, Baek HS, Yang S, et al. High neutrophil: lymphocyte ratio is associated with refractory Kawasaki disease. Pediatr Int. (2017) 59:669-74. doi: 10.1111/ped.13240

35. Wang CL, Wu YT, Liu CA, Lin MW, Lee CJ, Huang LT, et al. Expression of CD40 ligand on CD4+ T-cells and platelets correlated to the coronary artery lesion and disease progress in Kawasaki disease. Pediatrics. (2003) 111:E140-7. doi: 10.1542/peds.111.2.e140

36. Wang CL, Wu YT, Lee CJ, Liu HC, Huang LT, Yang KD. Decreased nitric oxide production after intravenous immunoglobulin treatment in patients with Kawasaki disease. J Pediatr. (2002) 141:560-5. doi: 10.1067/mpd.2002.127505

37. Kuo HC, Yang KD, Liang CD, Bong CN Yu HR, Wang L, et al. The relationship of eosinophilia to intravenous immunoglobulin treatment failure in Kawasaki disease. Pediatr Allergy Immunol. (2007) 18:3549. doi: 10.1111/j.1399-3038.2007.00516.x

38. Kuo HC, Wang CL, Liang CD Yu HR, Huang CF, Wang L, et al. Association of lower eosinophil-related T helper 2 (Th2) cytokines with coronary artery lesions in Kawasaki disease. Pediatr Allergy Immunol. (2009) 20:26672. doi: 10.1111/j.1399-3038.2008.00779.x

39. Guo MM, Tseng WN, Ko CH, Pan HM, Hsieh KS, Kuo HC. Th17- and Treg-related cytokine and mRNA expression are associated with acute and resolving Kawasaki disease. Allergy. (2015) 70:310-8. doi: 10.1111/all.12558

40. Kuo HC, Onouchi Y, Hsu YW, Chen WC, Huang JD, Huang YH, et al. Polymorphisms of transforming growth factor-beta signaling pathway and Kawasaki disease in the Taiwanese population. J Hum Genet. (2011) 56:8405. doi: 10.1038/jhg.2011.113

41. Jinkawa A, Shimizu M, Nishida K, Kaneko S, Usami M, Sakumura N, et al. Cytokine profile of macrophage activation syndrome associated with Kawasaki disease. Cytokine. (2019) 119:52-6. doi: 10.1016/j.cyto.2019.03.001

42. Nigrovic LE, Nigrovic PA, Harper MB, Chiang VW. Extreme thrombocytosis predicts Kawasaki disease in infants. Clin Pediatr. (2006) 45:44652. doi: $10.1177 / 0009922806289621$

43. Takahashi K, Oharaseki T, Naoe S, Wakayama M, Yokouchi Y. Neutrophilic involvement in the damage to coronary arteries in acute stage of Kawasaki disease. Pediatr Int. (2005) 47:305-10. doi: 10.1111/j.1442-200x.2005.02049.x

44. Kobayashi M, Matsumoto Y, Ohya M, Harada K, Kanno H. Histologic and immunohistochemical evaluation of infiltrating inflammatory cells in Kawasaki disease arteritis lesions. Appl Immunohistochem Mol Morphol. (2021) 29:62-7. doi: 10.1097/PAI.0000000000000860

45. Singh S, Agarwal S, Bhattad S, Gupta A, Suri D, Rawat A, et al. Kawasaki disease in infants below 6 months: a clinical conundrum? Int J Rheum Dis. (2016) 19:924-8. doi: 10.1111/1756-185X.12854

46. McCrindle BW, Rowley AH, Newburger JW, Burns JC, Bolger AF, Gewitz $M$, et al. Diagnosis, treatment, and long-term management of Kawasaki disease: a scientific statement for health professionals from the American Heart Association. Circulation. (2017) 135:e92799. doi: 10.1161/CIR.0000000000000484

47. Witt MT, Minich LL, Bohnsack JF, Young PC. Kawasaki disease: more patients are being diagnosed who do not meet American Heart Association criteria. Pediatrics. (1999) 104:e10. doi: 10.1542/peds.104.1.e10

48. Sudo D, Monobe Y, Yashiro M, Mieno MN, Uehara R, Tsuchiya K, et al. Coronary artery lesions of incomplete Kawasaki disease: a nationwide survey in Japan. Eur J Pediatr. (2012) 171:651-6. doi: 10.1007/s00431-011-1630-3

49. Gomard-Mennesson E, Landron C, Dauphin C, Epaulard O, Petit C, Green L, et al. Kawasaki disease in adults: report of 10 cases. Medicine. (2010) 89:149-58. doi: 10.1097/MD.0b013e3181df193c

50. Mitani Y, Tsuda E, Kato H, Higaki T, Fujiwara M, Ogawa S, et al. Emergence and characterization of acute coronary syndrome in adults after confirmed or missed history of Kawasaki disease in Japan: a Japanese Nationwide Survey. Front Pediatr. (2019) 7:275. doi: 10.3389/fped.2019.0 0275

51. Lin MT, Fu CM, Huang SK, Huang SC, Wu MH. Population-based study of Kawasaki disease shock syndrome in Taiwan. Pediatr Infect Dis J. (2013) 32:1384-6. doi: 10.1097/INF.0b013e31829efae6

52. Chen PS, Chi H, Huang FY, Peng CC, Chen MR, Chiu NC. Clinical manifestations of Kawasaki disease shock syndrome: a case-control study. J Microbiol Immunol Infect. (2015) 48:43-50. doi: 10.1016/j.jmii.2013.06.005

53. Gamez-Gonzalez LB, Moribe-Quintero I, Cisneros-Castolo M, Varela-Ortiz J, Munoz-Ramirez M, Garrido-Garcia M, et al. Kawasaki disease shock syndrome: unique and severe subtype of Kawasaki disease. Pediatr Int. (2018) 60:781-90. doi: 10.1111/ped.13614

54. Li Y, Zheng Q, Zou L, Wu J, Guo L, Teng L, et al. Kawasaki disease shock syndrome: clinical characteristics and possible use of IL-6, IL-10 and IFNgamma as biomarkers for early recognition. Pediatr Rheumatol Online J. (2019) 17:1. doi: 10.1186/s12969-018-0303-4

55. Prokic D, Ristic G, Paunovic Z, Pasic S. Pancreatitis and atypical Kawasaki disease. Pediatr Rheumatol Online J. (2010) 8:8. doi: 10.1186/1546-0096-8-8

56. Watanabe T. Clinical features of acute kidney injury in patients with Kawasaki disease. World J Clin Pediatr. (2018) 7:83-8. doi: 10.5409/wjcp.v7.i3.83

57. Ono R, Shimizu M, Yamamoto K, Umehara N, Manabe A. Kawasaki disease shock syndrome: case report and cytokine profiling. Pediatr Int. (2019) 61:620-2. doi: 10.1111/ped.13864

58. Kanegaye JT, Wilder MS, Molkara D, Frazer JR, Pancheri J, Tremoulet AH, et al. Recognition of a Kawasaki disease shock syndrome. Pediatrics. (2009) 123:e783-9. doi: 10.1542/peds.2008-1871

59. Kuo HC, Yang KD, Chang WC, Ger LP, Hsieh KS. Kawasaki disease: an update on diagnosis and treatment. Pediatr Neonatol. (2012) 53:411. doi: 10.1016/j.pedneo.2011.11.003

60. Rife E, Gedalia A. Kawasaki disease: an update. Curr Rheumatol Rep. (2020) 22:75. doi: 10.1007/s11926-020-00941-4

61. Holman RC, Christensen KY, Belay ED, Steiner CA, Effler PV, Miyamura J, et al. Racial/ethnic differences in the incidence of Kawasaki syndrome among children in Hawaii. Hawaii Med J. (2010) 69:194-7.

62. Nakamura Y. Kawasaki disease: epidemiology and the lessons from it. Int $J$ Rheum Dis. (2018) 21:16-9. doi: 10.1111/1756-185X.13211

63. Khor CC, Davila S, Breunis WB, Lee YC, Shimizu C, Wright VJ, et al. Genome-wide association study identifies FCGR2A as a susceptibility locus for Kawasaki disease. Nat Genet. (2011) 43:1241-6. doi: 10.1038/ng.981

64. Lee YC, Kuo HC, Chang JS, Chang LY, Huang LM, Chen MR, et al. Two new susceptibility loci for Kawasaki disease identified through genome-wide association analysis. Nat Genet. (2012) 44:522-5. doi: 10.1038/ng.2227

65. Onouchi Y. The genetics of Kawasaki disease. Int J Rheum Dis. (2018) 21:26-30. doi: 10.1111/1756-185X.13218

66. Kato S, Kimura M, Tsuji K, Kusakawa S, Asai T, Juji T, et al. HLA antigens in Kawasaki disease. Pediatrics. (1978) 61:252-5.

67. Oh JH, Han JW, Lee SJ, Lee KY, Suh BK, Koh DK, et al. Polymorphisms of human leukocyte antigen genes in korean children with Kawasaki disease. Pediatr Cardiol. (2008) 29:402-8. doi: 10.1007/s00246-007-9146-3

68. Huang Y, Lee YJ, Chen MR, Hsu CH, Lin SP, Sung TC, et al. Polymorphism of transmembrane region of MICA gene and Kawasaki disease. Exp Clin Immunogenet. (2000) 17:130-7. doi: 10.1159/000019132 
69. Huang FY, Chang TY, Chen MR, Hsu CH, Lee HC, Lin SP, et al. Genetic variations of HLA-DRB1 and susceptibility to Kawasaki disease in Taiwanese children. Hum Immunol. (2007) 68:69-74. doi: 10.1016/j.humimm.2006.10.018

70. Chen MR, Chang TY, Chiu NC, Chi H, Yang KD, Chang L, et al. Validation of genome-wide associated variants for Kawasaki disease in a Taiwanese casecontrol sample. Sci Rep. (2020) 10:11756. doi: 10.1038/s41598-020-68673-0

71. Onouchi Y. Molecular genetics of Kawasaki disease. Pediatr Res. (2009) 65:46R-54R. doi: 10.1203/PDR.0b013e31819dba60

72. Kuo HC, Chang JC, Guo MM, Hsieh KS, Yeter D, Li SC, et al. Gene-gene associations with the susceptibility of Kawasaki disease and coronary artery lesions. PLoS ONE. (2015) 10:e0143056. doi: 10.1371/journal.pone.0143056

73. Kuo HC, Chang JC, Kuo HC Yu HR, Wang CL, Lee CP, et al. Identification of an association between genomic hypomethylation of FCGR2A and susceptibility to Kawasaki disease and intravenous immunoglobulin resistance by DNA methylation array. Arthritis Rheumatol. (2015) 67:82836. doi: 10.1002/art.38976

74. Huang YH Li SC, Huang LH, Chen PC, Lin YY, Lin CC, et al. Identifying genetic hypomethylation and upregulation of Toll-like receptors in Kawasaki disease. Oncotarget. (2017) 8:11249-58. doi: 10.18632/oncotarget. 14497

75. Chen KD, Huang YH, Ming-Huey Guo M, Lin TY, Weng WT, Yang HJ, et al. The human blood DNA methylome identifies crucial role of betacatenin in the pathogenesis of Kawasaki disease. Oncotarget. (2018) 9:2833750. doi: 10.18632/oncotarget.25305

76. Huang LH, Kuo HC, Pan CT, Lin YS, Huang YH, Li SC. Multiomics analyses identified epigenetic modulation of the S100A gene family in Kawasaki disease and their significant involvement in neutrophil transendothelial migration. Clin Epigenetics. (2018) 10:135. doi: 10.1186/s13148-0180557-1

77. Kuo HC, Hsieh KS, Ming-Huey Guo M, Weng KP, Ger LP, Chan WC, et al. Next-generation sequencing identifies micro-RNA-based biomarker panel for Kawasaki disease. J Allergy Clin Immunol. (2016) 138:122730. doi: 10.1016/j.jaci.2016.04.050

78. Ni FF Li CR, Li Q, Xia Y, Wang GB, Yang J. Regulatory T cell microRNA expression changes in children with acute Kawasaki disease. Clin Exp Immunol. (2014) 178:384-93. doi: 10.1111/cei.12418

79. Freudenberg K, Lindner N, Dohnke S, Garbe AI, Schallenberg S, Kretschmer K. Critical role of TGF-beta and IL-2 receptor signaling in Foxp3 induction by an inhibitor of DNA methylation. Front Immunol. (2018) 9:125. doi: 10.3389/fimmu.2018.00125

80. Shevach EM, Thornton AM. tTregs, pTregs, and iTregs: similarities and differences. Immunol Rev. (2014) 259:88-102. doi: 10.1111/imr. 12160

81. Zhao C, Li X, Yang Y, Li Z, Li M, Tan Q, et al. An analysis of Treg/Th17 cells imbalance associated microRNA networks regulated by moxibustion therapy on Zusanli (ST36) and Shenshu (BL23) in mice with collagen induced arthritis. Am J Transl Res. (2019) 11:4029-45.

82. Bettelli E, Carrier Y, Gao W, Korn T, Strom TB, Oukka M, et al. Reciprocal developmental pathways for the generation of pathogenic effector TH17 and regulatory T cells. Nature. (2006) 441:235-8. doi: 10.1038/nature04753

83. Kato H, Koike S, Yokoyama T. Kawasaki disease: effect of treatment on coronary artery involvement. Pediatrics. (1979) 63:175-9.

84. Terai M, Shulman ST. Prevalence of coronary artery abnormalities in Kawasaki disease is highly dependent on gamma globulin dose but independent of salicylate dose. J Pediatr. (1997) 131:888-93. doi: 10.1016/S0022-3476(97)70038-6

85. Newburger JW, Sleeper LA, McCrindle BW, Minich LL, Gersony W, Vetter VL, et al. Randomized trial of pulsed corticosteroid therapy for primary treatment of Kawasaki disease. N Engl J Med. (2007) 356:66375. doi: 10.1056/NEJMoa061235

86. Hamada H, Suzuki H, Abe J, Suzuki Y, Suenaga T, Takeuchi T, et al. Inflammatory cytokine profiles during Cyclosporin treatment for immunoglobulin-resistant Kawasaki disease. Cytokine. (2012) 60:6815. doi: 10.1016/j.cyto.2012.08.006

87. Kobayashi T, Saji T, Otani T, Takeuchi K, Nakamura T, Arakawa H, et al. Efficacy of immunoglobulin plus prednisolone for prevention of coronary artery abnormalities in severe Kawasaki disease (RAISE study): a randomised, open-label, blinded-endpoints trial. Lancet. (2012) 379:161320. doi: 10.1016/S0140-6736(11)61930-2

88. Takahashi K, Oharaseki T, Yokouchi Y, Yamada H, Shibuya K, Naoe S. A half-century of autopsy results-incidence of pediatric vasculitis syndromes, especially Kawasaki disease. Circ J. (2012) 76:964-70. doi: 10.1253/circj.CJ-11-0928

89. Chen S, Dong Y, Yin Y, Krucoff MW. Intravenous immunoglobulin plus corticosteroid to prevent coronary artery abnormalities in Kawasaki disease: a meta-analysis. Heart. (2013) 99:76-82. doi: 10.1136/heartjnl-2012-302126

90. Suda K. Thromboprophylaxis in patients with coronary aneurysms caused by Kawasaki disease. Nihon Rinsho. (2014) 72:1659-63.

91. Eleftheriou D, Levin M, Shingadia D, Tulloh R, Klein NJ, Brogan PA. Management of Kawasaki disease. Arch Dis Child. (2014) 99:7483. doi: 10.1136/archdischild-2012-302841

92. Stagi S, Rigante D, Lepri G, Matucci Cerinic M, Falcini F. Severe vitamin $\mathrm{D}$ deficiency in patients with Kawasaki disease: a potential role in the risk to develop heart vascular abnormalities? Clin Rheumatol. (2016) 35:186572. doi: 10.1007/s10067-015-2970-6

93. Garcia-Pavon S, Yamazaki-Nakashimada MA, Baez M, Borjas-Aguilar KL, Murata C. Kawasaki disease complicated with macrophage activation syndrome: a systematic review. J Pediatr Hematol Oncol. (2017) 39:44551. doi: 10.1097/MPH.0000000000000872

94. Xie T, Wang Y, Fu S, Wang W, Xie C, Zhang Y, et al. Predictors for intravenous immunoglobulin resistance and coronary artery lesions in Kawasaki disease. Pediatr Rheumatol Online J. (2017) 15:17. doi: 10.1186/s12969-017-0149-1

95. Nozawa T, Imagawa T, Ito S. Coronary-artery aneurysm in tocilizumabtreated children with Kawasaki's disease. N Engl J Med. (2017) 377:18946. doi: 10.1056/NEJMc1709609

96. Arane K, Mendelsohn K, Mimouni M, Mimouni F, Koren Y, Brik Simon $\mathrm{D}$, et al. Japanese scoring systems to predict resistance to intravenous immunoglobulin in Kawasaki disease were unreliable for Caucasian Israeli children. Acta Paediatr. (2018) 107:2179-84. doi: 10.1111/apa.14418

97. Tremoulet AH. Adjunctive therapies in Kawasaki disease. Int J Rheum Dis. (2018) 21:76-9. doi: 10.1111/1756-185X.13208

98. Ma L, Zhang YY, Yu HG. Clinical manifestations of Kawasaki disease shock syndrome. Clin Pediatr. (2018) 57:428-35. doi: 10.1177/0009922817729483

99. Esposito S, Polinori I, Rigante D. The Gut microbiota-host partnership as a potential driver of Kawasaki syndrome. Front Pediatr. (2019) 7:124. doi: 10.3389/fped.2019.00124

100. Sharif K, Sharif Y, Watad A, Yavne Y, Lichtbroun B, Bragazzi NL, et al. Vitamin D, autoimmunity and recurrent pregnancy loss: more than an association. Am J Reprod Immunol. (2018) 80:e12991. doi: 10.1111/aji. 12991

101. Arpaia N, Campbell C, Fan X, Dikiy S, van der Veeken J. deRoos P, et al. Metabolites produced by commensal bacteria promote peripheral regulatory T-cell generation. Nature. (2013) 504:451-5. doi: 10.1038/nature 12726

102. Singh P, Kumar M, Al Khodor S. Vitamin D deficiency in the gulf cooperation council: exploring the triad of genetic predisposition, the Gut microbiome and the immune system. Front Immunol. (2019) 10:1042. doi: 10.3389/fimmu.2019.01042

103. Hu P, Jiang GM, Wu Y, Huang BY, Liu SY, Zhang DD, et al. TNF-alpha is superior to conventional inflammatory mediators in forecasting IVIG nonresponse and coronary arteritis in Chinese children with Kawasaki disease. Clin Chim Acta. (2017) 471:76-80. doi: 10.1016/j.cca.2017.05.019

104. Wang Y, Qian SY, Yuan Y, Wang Q, Gao L, Chen X, et al. Do cytokines correlate with refractory Kawasaki disease in children? Clin Chim Acta. (2020) 506:222-7. doi: 10.1016/j.cca.2020.03.014

105. Cohen S, Tacke CE, Straver B, Meijer N, Kuipers IM, Kuijpers TW. A child with severe relapsing Kawasaki disease rescued by IL-1 receptor blockade and extracorporeal membrane oxygenation. Ann Rheum Dis. (2012) 71:205961. doi: 10.1136/annrheumdis-2012-201658

106. Best D, Millar J, Kornilov I, Sinelnikov Y, Chiletti R, Rycus P, et al. Extracorporeal membrane oxygenation for Kawasaki disease: two case reports and the Extracorporeal Life Support Organization experience 1999-2015. Perfusion. (2017) 32:609-12. doi: 10.1177/02676591177 01564 
107. Zhang H, Xie L, Xiao T. Extracorporeal membrane oxygenation support for cardiac dysfunction due to Kawasaki disease shock syndrome. Front Pediatr. (2019) 7:221. doi: 10.3389/fped.2019.00221

108. Mucida D, Park Y, Kim G, Turovskaya O, Scott I, Kronenberg M, et al. Reciprocal TH17 and regulatory $\mathrm{T}$ cell differentiation mediated by retinoic acid. Science. (2007) 317:256-60. doi: 10.1126/science.1145697

109. Castellani ML, Shaik-Dasthagirisaheb YB, Tripodi D, Anogeianaki A, Felaco P, Toniato E, et al. Interrelationship between vitamins and cytokines in immunity. J Biol Regul Homeost Agents. (2010) 24:385-90.

110. Jun JS, Jung YK, Lee DW. Relationship between vitamin D levels and intravenous immunoglobulin resistance in Kawasaki disease. Korean J Pediatr. (2017) 60:216-20. doi: 10.3345/kjp.2017.60. 7.216

111. Ilie PC, Stefanescu S, Smith L. The role of vitamin D in the prevention of coronavirus disease 2019 infection and mortality. Aging Clin Exp Res. (2020) 32:1195-8. doi: 10.1007/s40520-020-01570-8

112. Rhodes JM, Subramanian S, Laird E, Griffin G, Kenny RA. Perspective: vitamin D deficiency and COVID-19 severity - plausibly linked by latitude, ethnicity, impacts on cytokines, ACE2 and thrombosis. J Intern Med. (2021) 289:97-115. doi: 10.1111/joim.13149

113. Mohammad S, Mishra A, Ashraf MZ. Emerging role of vitamin $\mathrm{D}$ and its associated molecules in pathways related to pathogenesis of thrombosis. Biomolecules. (2019) 9:110649. doi: 10.3390/biom911 0649

114. Bassi EJ, Moraes-Vieira PM, Moreira-Sa CS, Almeida DC, Vieira LM, Cunha CS, et al. Immune regulatory properties of allogeneic adiposederived mesenchymal stem cells in the treatment of experimental autoimmune diabetes. Diabetes. (2012) 61:2534-45. doi: 10.2337/db110844

115. Li Y, Li H, Cao Y, Wu F, Ma W, Wang Y, et al. Placentaderived mesenchymal stem cells improve airway hyperresponsiveness and inflammation in asthmatic rats by modulating the Th17/Treg balance. Mol Med Rep. (2017) 16:8137-45. doi: 10.3892/mmr.2017.7605

116. Hough KP, Chanda D, Duncan SR, Thannickal VJ, Deshane JS. Exosomes in immunoregulation of chronic lung diseases. Allergy. (2017) 72:53444. doi: 10.1111/all.13086

117. Li X, Lu C, Fan D, Lu X, Xia Y, Zhao H, et al. Human umbilical mesenchymal stem cells display therapeutic potential in rheumatoid arthritis by regulating interactions between immunity and Gut microbiota via the aryl hydrocarbon receptor. Front Cell Dev Biol. (2020) 8:131. doi: 10.3389/fcell.2020. 00131

118. Chen S, Dong Y, Kiuchi MG, Wang J, Li R, Ling Z, et al. Coronary artery complication in Kawasaki disease and the importance of early intervention: a systematic review and meta-analysis. JAMA Pediatr. (2016) 170:115663. doi: 10.1001/jamapediatrics.2016.2055

119. Biezeveld M, Geissler J, Merkus M, Kuipers IM, Ottenkamp J, Kuijpers T. The involvement of $F_{C}$ gamma receptor gene polymorphisms in Kawasaki disease. Clin Exp Immunol. (2007) 147:106-11. doi: 10.1111/j.1365-2249.2006.03266.x

120. Chang LS, Ming-Huey Guo M, Lo MH, Kuo HC. Identification of increased expression of activating $\mathrm{Fc}$ receptors and novel findings regarding distinct IgE and IgM receptors in Kawasaki disease. Pediatr Res. (2021) 89:1917. doi: 10.1038/s41390-019-0707-y

121. Smith KG, Clatworthy MR. FcgammaRIIB in autoimmunity and infection: evolutionary and therapeutic implications. Nat Rev Immunol. (2010) 10:32843. doi: $10.1038 /$ nri2762

122. Shrestha S, Wiener HW, Olson AK, Edberg JC, Bowles NE, Patel H, et al. Functional FCGR2B gene variants influence intravenous immunoglobulin response in patients with Kawasaki disease. J Allergy Clin Immunol. (2011) 128:677-80. doi: 10.1016/j.jaci.2011.04.027

123. de-Oliveira MG, Lira AAL, Sgnotto FR, Inoue AHS, Santos LS, Nakamatsu BY, et al. Maternal IgG impairs the maturation of offspring intrathymic IL-17-producing gammadeltaT cells: implications for murine and human allergies. Clin Exp Allergy. (2019) 49:1000-12. doi: 10.1111/cea. 13393

124. Inoue AHS, Lira AAL, de-Oliveira MG, de Sousa TR, Sgnotto FDR, Duarte $A$, et al. The potential of IgG to induce murine and human thymic maturation of IL-10+ B Cells (B10) revealed in a pilot study. Cells. (2020) 9:102239. doi: 10.3390/cells9102239

125. Victor JR. Do different IgG repertoires play a role in B- and Tcell functional modulation during ontogeny? The "hooks without bait" theory. Immunol Cell Biol. (2020) 98:540-8. doi: 10.1111/imcb. 12335

126. Fong DC, Brauweiler A, Minskoff SA, Bruhns P, Tamir I, Mellman I, et al Mutational analysis reveals multiple distinct sites within $\mathrm{Fc}$ gamma receptor IIB that function in inhibitory signaling. J Immunol. (2000) 165:445362. doi: 10.4049/jimmunol.165.8.4453

127. Coxon $\mathrm{CH}$, Geer $\mathrm{MJ}$, Senis YA. ITIM receptors: more than just inhibitors of platelet activation. Blood. (2017) 129:340718. doi: 10.1182/blood-2016-12-720185

128. Debre M, Bonnet MC, Fridman WH, Carosella E, Philippe N, Reinert $\mathrm{P}$, et al. Infusion of $\mathrm{Fc}$ gamma fragments for treatment of children with acute immune thrombocytopenic purpura. Lancet. (1993) 342:9459. doi: 10.1016/0140-6736(93)92000-J

129. Thiruppathi M, Sheng JR Li L, Prabhakar BS, Meriggioli MN. Recombinant IgG2a Fc (M045) multimers effectively suppress experimental autoimmune myasthenia gravis. J Autoimmun. (2014) 52:64-73. doi: 10.1016/j.jaut.2013.12.014

130. Jefferis R. Glycosylation as a strategy to improve antibody-based therapeutics. Nat Rev Drug Discov. (2009) 8:226-34. doi: 10.1038/ $\operatorname{nrd} 2804$

131. Yamada K, Ito K, Furukawa J, Nakata J, Alvarez M, Verbeek JS, et al. Galactosylation of IgG1 modulates FcgammaRIIB-mediated inhibition of murine autoimmune hemolytic anemia. J Autoimmun. (2013) 47:10410. doi: 10.1016/j.jaut.2013.09.001

132. Alter G, Ottenhoff THM, Joosten SA. Antibody glycosylation in inflammation, disease and vaccination. Semin Immunol. (2018) 39:102-10. doi: 10.1016/j.smim.2018.05.003

133. Tian RR, Zhang MX, Liu M, Fang X, Li D, Zhang L, et al. CD24Fc protects against viral pneumonia in simian immunodeficiency virusinfected Chinese rhesus monkeys. Cell Mol Immunol. (2020) 17:8878. doi: 10.1038/s41423-020-0452-5

134. Chen GY, Tang J, Zheng P, Liu Y. CD24 and Siglec-10 selectively repress tissue damage-induced immune responses. Science. (2009) 323:17225. doi: 10.1126/science.1168988

135. Sammar M, Siwetz M, Meiri H, Fleming V, Altevogt P, Huppertz B. Expression of CD24 and Siglec-10 in first trimester placenta: implications for immune tolerance at the fetal-maternal interface. Histochem Cell Biol. (2017) 147:565-74. doi: 10.1007/s00418-016-1531-7

136. Altevogt P, Sammar M, Huser L, Kristiansen G. Novel insights into the function of CD24: A driving force in cancer. Int J Cancer. (2021) 148:54659. doi: 10.1002/ijc.33249

137. Delaveris C, Wilk A, Riley N, Stark J, Yang S, Rogers A, et al. Synthetic Siglec-9 agonists inhibit neutrophil activation associated with COVID-19. ChemRxiv. (2020) 2020:chemrxiv.13378148. doi: 10.26434/chemrxiv.13378148

138. Li SM, Liu WT, Yang F, Yi QJ, Zhang S, Jia HL. Phosphorylated proteomics analysis of human coronary artery endothelial cells stimulated by Kawasaki disease patients serum. BMC Cardiovasc Disord. (2019) 19:21. doi: 10.1186/s12872-018-0982-2

139. Delaveris CS, Chiu SH, Riley NM, Bertozzi CR. Modulation of immune cell reactivity with cis-binding Siglec agonists. Proc Natl Acad Sci USA. (2021) 118:e2012408118. doi: 10.1073/pnas.2012408118

140. Porritt RA, Paschold L, Rivas MN, Cheng MH, Yonker LM, Chandnani $\mathrm{H}$, et al. HLA class I-associated expansion of TRBV11-2 T cells in multisystem inflammatory syndrome in children. J Clin Invest. (2021) 131:JCI146614. doi: 10.1172/JCI146614

141. Crayne CB, Albeituni S, Nichols KE, Cron RQ. The immunology of macrophage activation syndrome. Front Immunol. (2019) 10:119. doi: 10.3389/fimmu.2019.00119

142. Wang F, Zhang S, Jeon R, Vuckovic I, Jiang X, Lerman A, et al. Interferon gamma induces reversible metabolic reprogramming of M1 macrophages to sustain cell viability and pro-inflammatory activity. EBioMedicine. (2018) 30:303-16. doi: 10.1016/j.ebiom.2018. 02.009 
143. Grom AA, Horne A, De Benedetti F. Macrophage activation syndrome in the era of biologic therapy. Nat Rev Rheumatol. (2016) 12:25968. doi: 10.1038/nrrheum.2015.179

144. Pilania RK, Jindal AK, Johnson N, Prithvi A, Vignesh P, Suri D, et al. Macrophage activation syndrome in children with Kawasaki disease: an experience from a tertiary care hospital in northwest India. Rheumatology. (2020) 2020:keaa715. doi: 10.1093/rheumatology/keaa715

145. Lind-Holst M, Hartling UB, Christensen AE. High-dose anakinra as treatment for macrophage activation syndrome caused by refractory Kawasaki disease in an infant. BMJ Case Rep. (2019) 12:229708. doi: 10.1136/bcr-2019-229708
Conflict of Interest: The authors declare that the research was conducted in the absence of any commercial or financial relationships that could be construed as a potential conflict of interest.

Copyright (c) 2021 Chang, Yang, Lin and Yang. This is an open-access article distributed under the terms of the Creative Commons Attribution License (CC BY). The use, distribution or reproduction in other forums is permitted, provided the original author(s) and the copyright owner(s) are credited and that the original publication in this journal is cited, in accordance with accepted academic practice. No use, distribution or reproduction is permitted which does not comply with these terms. 